Desain Didaktis Pembelajaran.... (Frananda Ayu Julianti, Nyiayu Fahriza F., Miftha Indasari)

\title{
DESAIN DIDAKTIS PEMBELAJARAN BILANGAN CACAH UNTUK KELAS III SD
}

\author{
Oleh : Frananda Ayu Julianti, Nyiayu Fahriza Fuadiah, Miftah Indasari \\ Email : nyiayufahriza@gmail.com, mifthaindasari21@gmail.com
}

(Universitas PGRI Palembang)

\begin{abstract}
Abstrak
Penelitian desain mempunyai model berupa bentuk khusus yang mengacu pada studi validasi dan studi pengembangan yaitu Penelitian Desain Didaktis. Hanya saja penggunaan desain didaktis menunjukkan adanya penekanan pada aspek didaktik dalam desain pembelajaran yang lebih mengacu pada teori pembelajaran mikro. Hambatan dapat disebabkan oleh beberapa faktor yaitu hambatan asal didaktis (akibat sistem pendidikan) dan hambatan epistemologis (pengetahuan siswa yang memiliki konteks aplikasi terbatas).
\end{abstract}

Kata Kunci : Desain Didaktis Pembelajaran, Bilang Cacah

\section{DIDACTICAL DESIGN OF LEARNING TALKING NUMBERS FOR CLASS III SD}

\begin{abstract}
Design research has a model that is a special form, which refers to the validation study and development study, namely Didactical Design Research. It's just the use of didactical design shows that there is an emphasis on didactic aspects in the design of learning that refers to more micro learning theories. Barriers (obstacles) according to Brosseau (2002: 86) can be caused by several factors, namely obstacle of didactical origin (due to the education system) and obstacle of epistemological (students' knowledge that has a limited application context).
\end{abstract}

Keywords: Didactical Design of Learning, Talking Number

\section{A. PENDAHULUAN}

Pendidikan matematika memiliki peran yang sangat penting karena matematika merupakan ilmu dasar yang digunakan secara luas dalam berbagai bidang keidupan. Melalui pembelajaran matematika, siswa diharapkan dapat menumbuhkan kemampuan berpikir kritis, logis, sistematis, cermat, efektif, dan efisien dalam memecahkan masalah. Pembelajaran matematika di sekolah dasar merupakan upaya untuk menguatkan siswa agar terbiasa dengan pembelajaran berhitung seperti menambah, mengurangi, mengkali, dan membagi. 
Siswa dilatih untuk bisa menyelesaikan faktor-faktor yang berkaitan dengan soal-soal matematika. Belajar matematika tersebut harus didahului oleh adanya suatu masalah dan tujuannya adalah memperoleh solusi atas permasalahan tersebut sebagai aktualisasi keberhasilan diperolehnya makna matematis (Suryadi, 2013). Salah satu materi yang ada di dalam pembelajaran matematika di sekolah dasar adalah materi tentang bilangan pecahan dimana siswa sekolah dasar mulai mempelajari bilangan pecahan dimulai dari kelas 3, 4, 5, 6 .

Kondisi tersebut memungkinkan terjadinya perbedaan dalam penerimaan materi, sehingga berakibat pada perbedaan hasil belajar siswa. Kemampuan awal siswa akan berpengaruh terhadap pemahaman siswa pada materi selanjutnya dan jika hambatan tersebut terus dibiarkan maka siswa akan mengalami kesulitan yang bersifat kumulatif karena materi pembelajaran matematika diajarkan secara berjenjang atau bertahap, yaitu dari hal konkret ke abstrak, atau ke konsep yang lebih sukar.

Salah satu cabang dari kajian dalam matematika di tingkat sekolah dasar adalah operasi hitung pada bilangan cacah. Kesulitan-kesulitan dalam menyelesaikan soal tidak dialami oleh siswa yang mempunyai kemampuan di bawah rata-rata saja, akan tetapi dapat dialami oleh siswa dengan tingkat kemampuan manapun dan dari kelompok manapun dengan tingkat dan jenis kemampuan yang beragam.

Kesalahan inilah yang biasa disebut dengan hambatan belajar (learning obstacle). Hambatan-hambatan (obstacles) tersebut menurut Brousseau (2002) dapat disebabkan oleh beberapa faktor, yaitu obstacle of ontogenic origin (kesiapan mental belajar siswa), obstacle of didactical origin (akibat sistem pendidikan) dan obstacle of epistemological origin (pengetahuan siswa yang memiliki konteks aplikasi yang terbatas). Suryadi (2016:40) terdapat 3 (tiga) faktor penyebab hambatan belajar (learning obstacle) yaitu hambatan ontogeny (kesiapan mental belajar), didaktis (akibat pengajaran guru) dan epistemology (pengetahuan siswa yang memiliki konteks aplikasi yang terbatas).

Dalam proses pembelajaran matematika, bahan ajar adalah bahan atau materi pelajaran yang disusun secara sistematis, yang digunakan guru dan siswa. 
Bahan ajar yang dimaksud ialah bahan ajar yang berupa buku teks panduan guru dan buku teks lainnya yang dapat dijadikan dalam proses pembelajaran matematika disekolah dasar. Akan tetapi, kebanyakan guru menggunakan buku teks sebagai bahan ajar satu-satunya untuk menunjang proses pembelajaran tanpa melihat buku teks lainnya yang berkaitan dengan materi pelajaran matematika salah satunya materi operasi hitung pada bilangan cacah kelas III SD. Hal ini yang sering menyebabkan hambatan belajar.

Operasi hitung pada bilangan cacah yang dipelajari siswa di SD/MI, adalah himpunan bilangan yang dimulai dari angka 0 (nol) dan bilangan ini selalu bertambah satu dari bilangan sebelumnya, atau bisa juga disebut himpunan bilangan bulat yang bukan negatif, dan bilangan cacah juga bisa diartikan sebagai himpunan bilangan asli ditambah dengan angka nol.

\section{Pengertian Konsep Bilangan Cacah}

Di Indonesia, siswa telah mempelajari bilangan cacah sejak di Sekolah Dasar. Hal ini mengakibatkan siswa mengalami kesulitan dalam mempelajari bilangan cacah lebih lanjut, terutama menyelesaikan masalah dalam bentuk soal cerita dan masalah yang berkaitan dengan bilangan cacah dalam mata pelajaran yang lain. Bahkan pemahaman siswa yang kurang terhadap bilangan cacah dapat menjadi salah satu penyebab rendahnya pencapaian mereka dalam materi bilangan cacah di tingkat Sekolah Dasar.

Kesulitan siswa dalam mempelajari materi bilangan cacah di Sekolah Dasar telah dikemukakan oleh beberapa peneliti terdahulu yang meneliti tentang kesulitan belajar matematika yang dialami oleh siswa. Dalam penelitian-penelitian yang dilakukan tersebut, kesulitan-kesulitan siswa dalam mempelajari pecahan diidentifikasi sebagai wujud dari hambatan belajar (Learning Obstacles) yang dialami siswa.

\section{Theory Of Didactical Situations In Mathematics (TDSM)}

Teori situasi didaktis diperkenalkan oleh Brosseau pada tahun tujuh puluhan, Brosseau (2002:34) membedakan situasi didaktis menjadi empat macam, 
1) Situasi Aksi

Situasi ini mendorong siswa untuk memahami permasalahan yang diberikan dan menciptakan strategi agar dapat memecahkan atau menemukan solusi dari permasalahan tersebut.

2) Situasi Formulasi

Pada situasi ini siswa harus menyatukan pemahaman dan strategi yang telah didapatkan sebelumnya untuk didiskusikan bersama siswa lainnya baik secara berpasangan atau berkelompok. Siswa berdiskusi untuk menentukan strategi mana agar dapat menemukan solusi dari permasalahan.

3) Situasi Validasi

Pada situasi ini guru berperan untuk memvalidasi pemahaman siswa dan juga strategi yang telah siswa diskusikan sebelumnya, guru dapat memberikan penjelasan dan teori untuk memperjelas dan memperbaiki pemahaman dan strategi tersebut.

4) Situasi Institusionalisasi

Terdapat kemungkinan bahwa siswa memiliki situasi lain setelah menerima validasi dari guru, siswa dapat menggunakan pengetahuan yang didapatkan dari guru untuk dipublikasikan pada permasalahan lain.

\section{Hambatan Belajar (Learning Obstacle)}

Hambatan-hambatan (obstacles) tersebut menurut Brosseau (2002:86) dapat disebabkan oleh beberapa faktor, yaitu obstacle of didactical origin (akibat sistem pendidikan) dan obstacle of epistemological (pengetahuan siswa yang memiliki konteks aplikasi yang terbatas). Menurut Suryadi (2016:85) terdapat tiga faktor penyebab hambatan belajar (learning obstacle) yaitu hambatan ontogeni (kesiapan mental belajar), didaktis (akibat pengajaran guru) dan epistemologi (pengetahuan siswa yang memiliki konteks aplikasi yang terbatas).

\section{Hypothetical Learning Trajectory (HLT)}

Setiap tahap dari lintasan belajar terhadap tujuan pembelajaran yang dilaksanakan, guru harus memikirkan antisipasi dari reaksi siswa dalam 
merancang sebuah kegiatan di kelas untuk suatu topik tertentu. Dalam proses aktivitas pembelajaran, guru diharuskan mempunyai tindakan yang tepat untuk mengantisipasi aktivitas mental apa saja yang muncul dari siswa, tetapi memperhatikan tuuan dan pembelajaran itu sendiri. Prediksi dan antisipasi yang dilakukan guru tersebut hypothetical learning trajectory (HLT). Sehingga HLT dapat diartikan sebagai suatu prediksi aktivitas pembelajaran, seperti pemikiran siswa dan bagaimana pemahan siswa berkembang.

\section{Didactical Design Research}

Design research mempunyai model yang merupakan bentuk khusus, yang mengacu kepada validation study maupun development study yaitu Didactical Design Research. Hanya saja penggunaa desain didaktis (didactical design) menunjukan bahwa terdapat suatu penekanan pada aspek didaktik dalam perancangan pembelajaran yang mengacu kepada teori pembelajaran yang lebih mikro.

Sebelum menjelaskan model penelitian Didactical Design Research (DDR) menurut Suryadi (2009:45), terlebih dahulu akan dijelaskan teori tentang pembelajaran matematika yang beliau kembangkan yaitu metapedadidaktik. Teori ini sebenarnya dikembangkan tidak khusus untuk pembelajaran matematika tetapi juga pada pembelajaran bidang studi lainnya.

Dalam proses pembelajaran terjadi hubungan tiga serangkai (segitiga) antara guru, siswa, dan materi. Segitiga didaktis yang menggambarkan hubungan pedagogis (HP) antara guru dengan siswa serta hubungan didaktis (HD) antara siswa dengan materi merupakan aspek penting dalam pembelajaran. Aktivitas guru dalam pembelajaran diokuskan bukan pada siswa dan materi secara terpisah tetapi difokuskan terhadap hubungan antara siswa dan materi pada saat pembelajaran berlangsung.

Menurut Suryadi (2009:55), peran guru yang paling penting dalam konteks segitiga didaktis adalah: menciptakan suatu situasi didaktis (didactical situation) sehingga terjadi proses belajar dalam diri siswa (learning situation). Bahwa seorang guru selain perlu menguasai materi ajar, juga perlu memiliki pengetahuan 
Wahana Didaktika Vol. 18 No.3 September 2020 : 347-356

lain yang terkait dengan siswa serta mampu menciptakan situasi didaktis yang dapat mendorong proses belajar secara optimal.

\section{B. METODOLOGI PENELITIAN}

Dalam penelitian ini menggunakan metode design research dengan model Didactical Design Research untuk materi bilangan cacah. Suryadi (2009:74) mencetuskan bahwa ada 3 (tiga) tahapan dalam penelitian yang menggunakan kerangka penelitian desain didaktis (Didactical Design Research) yaitu, tahap pertama analisis situasi didaktis sebelum pembelajaran, tahap kedua analisis metapedadikdaktik, dan tahap ketiga analisis retrosfektif.

\section{HASIL PENELITIAN DAN PEMBAHASAN}

\section{Learning Obstacle Pada Materi Perkalian Dua Matriks}

Berdasarkan hasil identifikasi Learning obstacle terdapat beberapa learning obstacle yang dialami siswa pada materi pembelajaran bilangan cacah yang menyebabkan siswa kesulitan dalam memahami konsep pembelajaran bilangan cacah, hal ii diperkuat oleh pendapat Brousseau (Suryadi, 2016) yang menyebabkan bahwa learning obstacle adalah hambatan atau kesulitan belajar yang dihadapi siswa dalam proses belajar. Mengetahui learning obstacle pada siswa yang telah mempelajari pembelajaran bilangan cacah sebelumnya, dengan melakukan uji instrumen seperti memberikan tes learning obstacle. Tes ini diberikan berupa soal uraian dan terdapat soal materi prasyarat sebagai dasar untuk siswa belajar, sebelum masuk materi pembelajaran bilangan cacah.

Berdasarkan hasil analisis learning obstacle yang mucul adalah: 1) Kesalahan kurang memahami makna bilangan cacah 2) Kesalahan dalam menyebutkan kumpulan objek bilangan sampai 999 dengan benar 3) Kesalahan kurang teliiti membaca lambang bilangan 4) Kesalahan tidak menuliskan cara membilang 1000 sampai 10.000 dengan benar 5) Kesalahan kurang mampu menyelesaikan masalah sehari-hari yang berkaitan dengan bilangan cacah.

Kemudian menganalisis learning trajectory dengan mengkaji berbagai sumber belajar seperti buku yang dipakai guru saat mengajar didalam kelas, di 
aktifitas pembelajaran buku teks dalam proses pembelajaran sangatlah penting dan menjadi sumber utama yang dibutuhkan bagi guru maupun siswa, hal ini diperkuat oleh pendapat Fuadiah (2017) yang menyatakan buku teks merupakan salah satu sumber utama yang dibutuhkan guru maupun siswa itu sendiri untuk dijadikan bahan atau sebagai informasi dalam proses belajar mengajar di kelas.

Learning obstacle didapatkan juga dari wawancara guru mata pelajaran matematika, guru mrnyebutkan dalam wawanara tersebut bahwa siswa masih sulit dalam menentukan bilangan cacah dan masih sulit dalam menghitung jumlah bilangan cacah, karena itu perlu sesekali merancang suatu desain pembelajaran untuk mengatasi learning obstacle yang muncul.

Kemudian dari learning obstacle yang muncul peneliti membuat suatu Hypotetical Learning Trajectory (HLT) kemudian merancang suatu desain pembelajaran untuk mengatasinya adalah desain didaktis. HLT disusun berdasarkan teori learning trajectory. Setelah dari HLT yang sudah disusun kemudian dikembangkan menjadi suatu desain didaktis yang bertujuan untuk mengatasi learning obstacle yang muncul. Desain didaktis ini merupakan salah satu faktor penentu keberhasilan siswa dalam proses belajar mengajar, karena desain didaktis ini memuat struktur belajar yang berhubungan dengan interaksi guru-siswa-materi. Selain itu desain didaktis ini guru juga harus memikirkan kemungkinan masalah yang akan terjadi semacam prediksi respon siswa yang akan terjadi dan dari respon tersebut tentulah guru harus juga berfikir tentang antisipasi untuk mengatasi respon yang muncul.

Dengan desain didaktis ini tentang guru dapat mengatasi masalah didaktis yang terjadi dikelas serta dapat menciptakan interaksi belajar yang kondusif, kemudian dikembangkan juga suatu media pembelajaran yang nantinya dapat mendukung proses belajar mengajar didalam desain tersebut yang akan mempermudah siswa dalam memahami suatu konsep pembelajaran. Berdasarkan respon siswa yang muncul tentu ada antisipasi yang diberikan oleh pebeliti untuk mengatasi masalah-masalah yang mungkin terjadi saat pembelajaran. 


\section{Antisipasi Didaktis Pada Materi Pembelajaran Bilangan Cacah}

\section{Berdasarkan Learning Obstacle}

Teori situasi didaktis yang dikembangkan dalam penelitian ini adalah pemberian soal yang tertera. Sejalan dengan ungkapan Fuadiah (2017) tentang situasi didaktis yang diciptakan oleh guru melalui desain didaktis dalam kegiatan pembelajaran dikelas diharapkan untuk mengembangkan potensinya, melalui serangkaian proses abstrak yang bisa membangun pegetahuan mereka sendiri.

Dari situasi yang dikembangkan siswa merespon dengan baik perkembangan situasi didaktis tersebut, respon siswa yang ada sejalan lurus dengan situasi didaktis yang dikembangkan. Hal ini sejalan dengan Suryadi (2009) yang berkenan tentang respon siswa yang sudah diperediksi oleh guru didalam pembelajaran yang termuat pada aktivitas berfikir guru sebelum pembelajaran dimulai.

Situasi belajar terjadi disaat desain hipotetik diterapkan, situasi belajar benar-benar terjadi disepanjang tahapan yang dilalui sehingga siswa merespon situasi didaktis tersebut dengan baik, akan tetapi terdapat beberapa siswa yang tidak memberikan respon situasi didaktis semua itu dikarenakan siswa hanya sekedar mengikuti pembeajaran. Adapun demikan siswa belajar sungguh-sungguh agar berhasil dalam belajar dan menghadapi kesulitan yang ada.

Akan tetapi siswa tersebut berusaha memecahkan masalahnya dengan bertanya kepada guru ataupun kepada temannya sehingga siswa dapat mengkomunikasikan apa yang ada di dalam pikirannya. HLT dan desain didaktis dapat berubah dikarenakan setelah melakukan uji coba desain didaktis, uji coba desain didaktis dapat menjadi sebuah reisi yang akan menjadikan desain didaktis menjadi sempurna untuk kelas III SD Negeri 89 Palembang.

\section{Revisi HLT dan Desain Didaktis Hipotetik}

Berdasarkan Uji Coba Desain dan Analisis Metapedadidaktik Terdapat Beberapa Revisi Desain yaitu 1) Menentukan Konsep Pembelajaran Bilangan Cacah. Pada materi ini menentukan bilangan cacah dengan hasil revisinya, materi 
ini harus lebih dikembangkan lagi, agar siswa tidak keliru dalam mencoba jawab soal yang ada di tes identifikasi akhir tersebut.

\section{SIMPULAN}

Berdasarkan tujuan peneliti yaitu menganalisis learning obstacle dengan pembelajaran bilangan cacah dikelas III SD Negeri 89 Palembang dan desain didaktis berdasarkan learning obstacle, maka peneliti dapat menyimpulkan sebagai berikut:

1. Learning obstacle yang teriidentifikasi pada materi bilangan cacah yaitu:

a) Menjelaskan konsep pembelajaran bilangan cacah, siswa keliru dalam menjumlahkan bilangan cacah

b) Mengurutkan bilangan cacah, siswa tidak dapat mengurutkan bilangan cacah dari yang terkecil hingga sampai terbesar.

c) Konsep bilangan cacah dalam kehidupan sehari-hari, saat mengerjakan konsep pembelajaran bilangan cacah dalam kehidupan sehari-hari siswa salah dalam menerapkannya.

2. Desain didaktis yang disusun peneliti merupakan desain yang menggembangkan alur belajar HLT yang berisikan tujuan pembelajaran, tahapan situasi didiaktis, kegiatan siswa, prediksi respon siswa, antisipasi respon siswa dan waktu. Materi dalam desain didaktis ini yaitu:

a) Menjelaskan kembali konsep pembelajaran bilangan cacah, siswa diingatkan kembali konsep bilangan cacah dengan menjawab untuk mengembangkan alur berfikir siswa dan menemukan mana bilangan cacah tesebut.

b) Mengurutkan bilangan cacah. Siswa diperkenalkan dahulu tentang bilangan cacah, kemudian siswa akan mengurutkan bilangan cacah.

c) Sifat-sifat bilangan cacah. Siswa diingatkan kembali untuk sifat-sifat penjumlahan bilangan cacah dipergunakan untuk melanjutkan menentukan bilangan cacah. 


\section{DAFTAR PUSTAKA}

Brosseau (2002). Theory of Didactical Situation in Mathematics. The Netherlands: Kluwer Academic Publishers

Fuadiah, N. F (2017), Hypothetical learning trajectory pada pembelajaran bilangan pecahan berdasarkan teori situasi didaktis de sekolah dasar.

Masharafa, volume 6, nomor 1, 16.

Suryadi, D. (2009). Metapedadidaktik dalam Pembelajaran Matematika: Suatu Strategi Pengembangan Diri menuju Guru Profesional. Pidato Pengukuhan Guru Besar Universitas Pendidikan Indonesia, Bandung April 2009.

Suryadi, D. (2013). Didactical Design Research (DDR) Dalam Pengembangan Pembelajaran Matematika. Prosiding seminar nasional matematika dan pendidikan matematika Volume 1, Tahun 2013. ISSN 977-2338831., (hal. 3)

Suryadi, D. (2016). Didactical Design Research (DDR) Dengan Matematika Realistik Dalam Pengembangan Matematika. Makalah pada Seminar Nasional Matematika dan Pendidikan Matematika UNSWAGATI. 